IdeAs

Idées d'Amériques

$3 \mid 2012$

L'alimentation dans les Amériques au prisme des sciences sociales

\title{
Paul ESTRADE, Severiano de Heredia. Ce mulâtre cubain que Paris fit 'maire' et la République, ministre.
}

Paris, Les Indes Savantes, 2011, 166 p.

\section{Natacha VAISSET}

\section{(2) OpenEdition}

Journals

Édition électronique

URL : https://journals.openedition.org/ideas/542

DOI : 10.4000/ideas.542

ISSN : 1950-5701

Éditeur

Institut des Amériques

\section{Référence électronique}

Natacha VAISSET, «Paul ESTRADE, Severiano de Heredia. Ce mulâtre cubain que Paris fit 'maire' et la République, ministre. », IdeAs [En ligne], 3 | 2012, mis en ligne le 13 décembre 2012, consulté le 19 octobre 2022. URL : http://journals.openedition.org/ideas/542 ; DOI : https://doi.org/10.4000/ideas. 542

Ce document a été généré automatiquement le 19 octobre 2022.

\section{cc) (†)}

Creative Commons - Attribution - Pas d'Utilisation Commerciale - Pas de Modification 4.0 International - CC BY-NC-ND 4.0

https://creativecommons.org/licenses/by-nc-nd/4.0/ 


\section{Paul ESTRADE, Severiano de Heredia. Ce mulâtre cubain que Paris fit 'maire' et la République, ministre.}

Paris, Les Indes Savantes, 2011, 166 p.

Natacha VAISSET

\section{RÉFÉRENCE}

Paul ESTRADE, Severiano de Heredia. Ce mulâtre cubain que Paris fit « maire » et la République, ministre, Paris, Les Indes Savantes, 2011, 166 p.

1 Au sein de l'historiographie française, les études consacrées aux personnes de couleur originaires du continent latino-américain et ayant exercé une influence sur la vie politique et la société française sont encore rares, pour ne pas dire inexistantes. C'est en partant de ce constat et de sa connaissance profonde de Cuba que Paul Estrade, professeur émérite de l'Université de Paris 8 et spécialiste de l'Histoire de l'Amérique Latine contemporaine, a entrepris de mettre en lumière le parcours du CubanoFrançais Severiano de Heredia (1836-1901).

2 Né à La Havane, Severiano de Heredia est alors déclaré fils légitime d'un couple de mulâtres libres, mais également filleul du propriétaire terrien cubain Ignacio José de Heredia (proche parent des poètes José-María de Heredia et José María Heredia), qui serait en réalité son père naturel et qui, de fait, prendra à sa charge son éducation et en fera son héritier. Suite au décès prématuré de ce « père adoptif » marié à une Française, le jeune mulâtre élevé au rang d'aristocrate rentier suit un cursus classique au sein de l'établissement parisien Louis-le-Grand. Après une brève incursion peu concluante dans le monde des lettres (il publie notamment quelques poèmes), il devient chroniqueur culturel et affiche alors une préférence pour les œuvres contemporaines qui 
«signifie[nt] quelque chose, affirme[nt] un principe ou agite[nt] tout au moins un problème » (p. 35). Aux abords de la trentaine, il s'affirme comme journaliste, puis rédacteur en chef, d'un hebdomadaire littéraire où se manifestera peu à peu "son intérêt croissant pour la question sociale » (p. 36). C'est à la même période qu'il prend position en faveur des indépendantistes cubains, intègre la franc-maçonnerie parisienne et épouse une jeune veuve issue de la bourgeoisie française. C'est également à la fin des années 1860 qu'il entreprend les démarches en vue de l'obtention de la nationalité française, laquelle lui est accordée en 1870 et lui permet alors de se lancer légalement en politique.

3 De fait, dès sa naturalisation et en pleine guerre contre la Prusse (1870-1871), il rend publiques ses opinions politiques en apportant son soutien aux républicains. Celles-ci tiennent résolument $\mathrm{du}$ réformisme social comme le montre la place croissante qu'occuperont les problèmes sociaux au sein de ses programmes électoraux successifs. Défenseur inébranlable de la laïcité, il promeut l'école gratuite, laïque et obligatoire (y compris pour les jeunes filles), le travail des femmes et les sociétés de secours mutuels. En outre, il soutient généralement les revendications des ouvriers «tendant à l'augmentation, limitée, $\mathrm{d}[\mathrm{e}$ leur] salaire [...], à la réduction, modérée, de la journée de travail, à l'obligation de prendre des mesures d'hygiène » (p. 59).

4 Sa carrière politique commence en 1873 lorsqu'il est élu conseiller municipal (républicain) du quartier des Ternes (XVII ${ }^{\mathrm{e}}$ arrondissement de Paris), soutenu par les comités laïques et les loges maçonniques. Il l'est resté (toujours réélu au premier tour et même, en 1879, Président du Conseil) jusqu'en 1881, lorsqu'il est élu député de la Seine (1881-1885, pour l'Union Républicaine ; 1885-1889, pour la Gauche Radicale). En 1887, à l'apogée de sa carrière, le cabinet Rouvier lui confie le portefeuille de ministre des Travaux Publics. Constant dans ses idées (bien que progressivement plus modéré), il occupe très assidûment et énergiquement ces différents mandats.

5 Néanmoins, si, dans l'ensemble, ce portrait est celui d'un homme intelligent, sensible aux questions sociales, consciencieux et au parcours couronné de succès, l'auteur pointe également certaines contradictions du personnage et mentionne les traverses qu'il a rencontrées. Par exemple, comment interpréter sa pensée sociale lorsque l'on sait que la fortune dont il a hérité est le fruit du travail des esclaves de sa plantation cubaine? De fait, que vaut-elle émanant d'un rentier (voir ses investissements dans l'immobilier), doublé d'un patron (il possède une société de transports urbains) ? Paul Estrade n'élude pas ces paradoxes - déjà relevés à l'époque -, de même qu'il fait état des résistances auxquelles a dû faire face Severiano de Heredia: vraisemblablement premier ministre de couleur en France, son ascension dans la hiérarchie sociale semble avoir indigné (ou inquiété) certain notables si l'on en croit les quolibets à la fois racistes et xénophobes prononcés à son encontre.

6 Ainsi, au-delà de l'intérêt historique propre à la trajectoire de Severiano de Heredia, cet ouvrage centré sur un personnage du XIXe siècle actualise (paradoxalement) des questionnements très contemporains autour du concept (glissant) d'identité nationale, de la place des personnes de couleurs et des étrangers dans sa construction et dans celle de l'Histoire de France. Il aborde aussi la question de l'intégration des minorités et celles du colonialisme, de la laïcité (dont la séparation de l'Église et de l'État), du rôle de l'école républicaine ou de la formation pour adultes. Enfin, il y est également question de décentralisation, de gestion de l'argent public, d'aménagement du territoire, d'urbanisme et de transports en commun. En d'autres termes, l'étude menée par Paul 
Estrade confirme que, si la France est renommée pour la richesse de son patrimoine intellectuel (notamment), elle le doit en partie à la diversité et aux échanges nés des immigrations multiples.

7 Écrit sur le mode de la biographie - la structure d'ensemble, chronologique, est émaillée de chapitres thématiques -, cet ouvrage d'environ 160 pages s'adresse à un public large puisque, à la précision et au foisonnement des données historiques, l'auteur allie une écriture imagée, efficace et élégante, permettant ainsi au lecteur de redécouvrir plaisamment, par l'intermédiaire de la trajectoire de Severiano de Heredia, bien des aspects de la France de la fin du XIX siècle. En outre, la mise en perspective de ce destin individuel soulève des interrogations dont l'actualité est frappante et en fait resurgir d'autres que l'on a bien souvent ignorées, délibérément ou non, jusqu'à ce jour. Ainsi, on ne peut que saluer la démarche "d'exhumation » de la vie de Severiano de Heredia menée par Paul Estrade et remercier son auteur de nous rappeler que l'Histoire - individuelle et collective - peut trouver bien des échos dans l'analyse du temps présent.

\section{AUTEURS}

\section{NATACHA VAISSET}

Docteure en études latino-américaines de l'Université de Rennes 2 et A.T.E.R. de Civilisation Latino-américaine à l'Université Charles de Gaulle/Lille 3. Elle est également membre du Groupe d'Études Interdisciplinaire sur le Venezuela (GEIVEN). Email :

natachapointvaissetatgmailpointcom. 